\title{
ABSTRACTS OF MEMOIRS \\ RECORDING WORK DONE AT THE PLYMOUTH LABORATORY
}

The Resistance of Nerve in Relation to Interpolar Length

\author{
By J. F. Danielli \\ Fourn. Physiol., Vol. xcvi, 1939, pp. 65-73
}

Assuming that a nerve may be regarded as a conducting core surrounded by a resistant sheath, lying in a conducting medium, conductivity experiments have been made following Rushton's treatment, by which the several resistances can be determined. Errors, probably caused by uneven distribution of water over the surface of the nerve and by uneven contact with the electrodes, are so large that a rigorous test cannot be obtained for this hypothesis. The results obtained, however, are compatible with this theory.

Very large errors also enter into the measurement of $R$, the resistance across a nerve sheath. It has, however, been possible to show that for frog nerve the maximum change in $R$ for a $p H$ change from 6 to 8 is less than $\pm 10 \%$ of the value at $p \mathrm{H} 7$. Addition of $\mathrm{Ca}$ or $\mathrm{K}$ to bring the total in Ringer to ten times normal does not change by more than $\pm 30 \%$ of the value found in normal Ringer. Both $\mathrm{Ca}$ and $\mathrm{K}$ in these concentrations have very marked effects on the excitability of the nerve, so that it seems probable that the membrane on which these ions act gives rise to a relatively insignificant part of the total sheath resistance.

J. F. D.

\section{Factors in Cation Permeability}

By H. Davson and J. F. Danielli

Biochem. Fourn., Vol. xxxII, 1938, pp. 991-1001

The possibility that the high concentration gradient of $\mathrm{K}^{+}$maintained by the erythrocytes of many species against their surrounding plasma is due to an active metabolic process has been investigated. Metabolic poisons, such as $\mathrm{CN}$, $\mathrm{CO}$, urethane, and accelerators such as methylene blue and pyocyanine had no influence on the $\mathrm{K}^{+}$content of the non-nucleated erythrocytes of the rabbit and the nucleated cells of the goose and dogfish. Fluoride caused a small loss of $\mathrm{K}^{+}$, but it was concluded that this is not associated directly with the inhibition of glycolysis produced by this substance.

The extent to which losses of $\mathrm{K}^{+}$may be caused by centrifuging the cells from serum or saline was studied. Direct proof of such losses was obtained 
with the erythrocytes of the dogfish and ox. The possible bearing of these effects on earlier work is discussed.

The question as to whether haemolysis, however produced, is preceded by a state of cation permeability was studied. Subhaemolytic concentrations of amyl alcohol, the dihydric phenols and guaiacol caused losses of $\mathrm{K}+$ from the rabbit erythrocyte; digitonin, $\mathrm{Na}$ cholate and oleate caused losses only when in haemolytic concentrations (these losses were over and above those due to the haemolysis itself); saponin produced no loss of $\mathrm{K}+$ in all the concentrations studied. Acidity and alkalinity were only effective under haemolytic conditions, whilst raising the temperature caused considerable losses of $\mathrm{K}^{+}$; the penetration of $\mathrm{K}^{+}$into the erythrocytes of the ox from strongly hypotonic aqueous $\mathrm{KCl}$ was demonstrated. The haemolytic action of silver is preceded by an induced permeability to cations.

J. F. D.

The Colour Changes and Colour Patterns of Sepia officinalis L.

By William Holmes

Proc. Zool. Soc. London, $A$, Vol. cx, I940, pp. 17-36

The cuttlefish, Sepia officinalis, has the power to change its colour more strikingly developed than any other animal known. As the result of the variety of its chromatophore pigments, and the neuro-muscular nature of the chromatophore control, it can show a number not only of colours but also of patterns of colour on the surface of its mantle and head; and each pattern appears under specific conditions of stimulation. And its colour behaviour is made still more impressive by the fact that one pattern can be changed for another entirely different in times of less than a second.

The weight of evidence is in favour of the view that its powers of colour change and pattern production endow Sepia with a system of protective coloration unique in its complexity. Protection is afforded chiefly by various concealing patterns, each produced in the appropriate environment. But there are also patterns which may well be directed towards "terrifying" a predator. Further, it is suggested that in its power to change conspicuous patterns rapidly Sepia is provided with a protective colour device which does not fall into any category of Poulton's classification. This device depends on the fact that the pattern change gives the impression of rapid movement, and this movement will probably cause a "flight reaction" in the predator. For it is commonly observed, in fish for example, that any sudden movement in the visual field causes the animal to withdraw.

W. H. 


\title{
The Myenteric Nerve-PLEXUS IN SOME LOWer ChORDates
}

\author{
By P. Kirtisinghe
}

Quart. Fourn. Micr. Sci., Vol. Lxxxi, 1940, pp. 521-39

Preparations of the myenteric plexus in a few teleosts, in Scylliorhinus canicula, and in Amphioxus, stained chiefly with methylene blue and silver nitrate methods, showed a much simpler arrangement than in the higher forms. The neurons of the plexus in teleosts belong to Dogiel's types I and II, in Scylliorhinus only those of type II were found. In Amphioxus bipolar nerve cells are definitely present in addition to the stellate ganglion cells described by Boeke. Synapses between (a) the pre-ganglionic fibres and the enteric neurons, and (b) the enteric neurons themselves are figured and described. No connexion between the system of "interstitial cells" of Cajal and the enteric nerveplexuses was observed. The enteric plexuses of fish and Amphioxus are not in the form of a nerve-net. It is not possible to compare the enteric plexus of Amphioxus with the system of "interstitial cells" of the higher chordates. The stellate ganglion cells of Amphioxus are comparable to the neurons of type I in the higher forms. P. K.

\section{REPRODUCTION OF THE DOGFISH}

By H. Metten

Phil. Trans. Roy. Soc. London, B, Vol. ccxxx, 1939, pp. 217-38

Migration of ova from the ovary to the coelomic opening of the oviducts in Scylliorhinus canicula is entirely dependent upon ciliation, as it is in Amphibia. The entire peritoneal wall and many abdominal viscera of an adult female are ciliated. The cilia, which are absent in the male and immature female, direct a current of coelomic fluid towards the ostium. An ovum excised from the ovary of one adult female and inserted through an abdominal incision into the peritoneal coelom of another will undergo migration towards the ostium. The speed of the migration depends upon the region into which the ovum is introduced. An ovum placed in the bridge joining the two liver lobes will traverse the hepatic sinus, enter the ostium and descend an oviduct as far as the top of the oviducal gland, in three hours. There are no muscular movements of any of the organs concerned.

In addition to its function of secreting albumen and the egg-case, the oviducal gland of the dogfish is a receptaculum seminis. By triturating a portion of the shell-secreting zone of the gland in saline solution, active spermatozoa can be seen at all times of the year. There does not seem to be any sharply defined breeding season, but an increase in breeding activity is noticed in the spring. The oviducal glands of all adult females contain spermatozoa, but the sperm 
content is very variable. In preparations of resting glands, spermatozoa can be seen in the shell-secreting tubules, whilst in actively secreting glands, a proportion of these spermatozoa are emitted in the shell material. In this way fertilization of an ovum is practically ensured.

H. $M$.

\title{
Algal Production and the Food ReQuirements of a Limpet
}

\author{
By H. B. Moore \\ Proc. Malacol. Soc., Vol. xxiII, 1938, pp. II7-18
}

On the outer wall of the new swimming pool at Tinside, Plymouth, a thick algal felt had developed, and in this a number of limpets (Patella vulgata) had eaten clear patches. By measuring the sizes of the cleared areas and of the limpets on them it was estimated that in their first year these individuals require an area of about $75 \mathrm{sq}$. $\mathrm{cm}$. per c.c. of limpet to support themselves, food being provided both by clearing the edges and by cropping the already cleared area.

H. B. M.

\section{The Colonization of a New Rocky Shore at Plymouth}

By H. B. Moore

Fourn. Anim. Ecol., Vol. viII, 1939, pp. 29-38

A newly made stony beach and a concrete wall at Tinside, Plymouth, were kept under observation for two years after their completion. The time of arrival, abundance and growth-rate of the colonizing species of animals and algae were noted and compared with a neighbouring long-established beach. The results indicated rapid colonization by a few hardy species and very slow colonization by most others. It appeared further that the latter were deterred, not by overcrowding, but by some environmental condition particularly unfavourable to the young stages, since those individuals which succeeded in establishing themselves showed a quite normal growth rate.

H. B. M.

\section{Further Observations on the Colonization of a New Rocky Shore at Plymouth}

By H. B. Moore and N. G. Sproston

Gourn. Anim. Ecol., Vol. 1x, 1940, pp. 319-27

The state of colonization of the flora and fauna on a new concrete wall and stony beach at Plymouth after six years is described, for comparison with a previous survey made during the first two years (Moore, 1939: see above). Fourteen species of Algae and seventy-one species of animals were found. The highest and lowest zones of the beach appear to have developed more quickly towards a climax than the intermediate zone, in which environmental conditions are less favourable than in the others.

N. G. S. 
Some Observations on the Growth of Peringia ulvaE (Pennant) i 777 IN THE LABORATORY

\section{By Anne Rothschild and Miriam Rothschild}

Novitates Zool., Vol. XII, I939, pp. 240-7

A comparison was made between the growth-rate of Peringia ulvae, a brackish water Gastropod, collected from two different habitats and kept in the laboratory in (a) glass bowls, and $(b)$ glass tubes. It was found that the snails kept in the bowls grew considerably faster, and that their size, consequently, is no criterion of their age. It was also found that apart from the different rapidity of increase in size the specimens in bowls and tubes displayed certain differences in their growth curve. When reared in the laboratory specimens collected from the mud-flats and saltings, which in nature differ from each other in size, shell shape, shell colour and shell texture, show no such variation, and it therefore seems probable that these differences are due to environmental rather than genetic factors. The snails parasitized by trematodes grew faster than uninfected specimens, thus supporting the theory that these infections cause increased growth. It was also found that uninfected females grew faster than uninfected males, and it seems probable that the larger size of females in nature is due to increased growth-rate rather than a longer life.

M. R.

\section{A Note on the Life CyCle OF CRYPTOCOTYLE LINGUA (CREPLiN) I825 (TREMATOdA) \\ By Miriam Rothschild}

Novitates Zool., Vol. XII, 1939, pp. I78-80

The life cycle of Cryptocotyle lingua was demonstrated experimentally in the laboratory. The cercariae were found parasitizing Littorina littorea; a number of fish, more especially in-shore forms such as wrasse, rockling, blennies and gobies, served as the intermediate host. The cercariae encysted in the fins and skin, and in those fish which are probably the natural hosts, stimulated the formation of pigment deposits round the cysts. The infected fish were kept in the laboratory a fortnight, and then fed to laboratory-reared albino rats, ducks and black-headed gulls. The adult worms were recovered from the intestine of the latter birds a month later. It was found that the behaviour of the cercaria is of importance for distinguishing between closely related species. The fertility of single infections proved to be very high. Littorina in the laboratory emitted cercariae for periods extending over three years, averaging about 300 cercariae per day.

M. R. 


\title{
Electrolyte Content and Action Potential of the GiANT NERVE Fibres OF LOLIGO
}

\author{
By D. A. Webb and J. Z. Young \\ fourn. Physiol., Vol. xcviri, 1940, pp. 299-313
}

Previous attempts to discover the physico-chemical basis of the resting and action potentials of nerve fibres have been handicapped by the presence in ordinary nerve trunks of connective tissue and intercellular fluid, which reduce the potentials by short-circuiting and introduce into the analyses an error of considerable but unknown magnitude. With the giant fibres of Loligo it is possible to isolate a single fibre, measure its resting and action potentials, and then submit it to chemical analysis. It is shown that the observed action potentials approximate closely to the diffusion potentials which would be produced if the bounding membrane of the axoplasm were permeable only to potassium ions, except during the passage of the impulse, when it is presumed to be freely permeable to all ions. The potentials may therefore be attributed largely, though not entirely, to the high concentration of intracellular potassium ( $0.28 M$, as against $0.01 M$ in sea water) and the differential permeability of the axon membrane. Chloride is present in the axoplasm at a concentration of O. I $M$, which, though only a fifth of the concentration in sea water, is far higher than the values reported for the cells of vertebrates. The electrolyte balance-sheet of the axoplasm reveals large osmotic and anion deficits, indicating the presence in considerable quantity of anions (and perhaps nonelectrolytes also) whose nature is not yet known.

D. A. W.

\section{Observations on the Coelenterate Nervous System}

\author{
By the late H. H. Woollard and J. A. Harpman \\ fourn. Anatomy, Vol. LxxIII, 1939, pp. 361-2
}

\section{Discontinuity in the Nervous System of Coelenterates}

By the late H. H. Woollard and J. A. Harpman

fourn. Anatomy, Vol. LxxIII, 1939, pp. 559-62

The histology of the nervous system in Cyanea lamarcki and Chrysaora isosceles, and in the tentacles of Actinia equina and Tealia felina, has been studied by the methods of methylene blue and gold chloride. In the jelly-fishes, nerve cells and fibres are most abundant in the sub-umbrellar region close to the sense organs.

The nerve cells are usually bipolar; multipolar cells are infrequent. The cells contain granules (stainable with methylene blue) which extend for a short 
distance into the cell processes. There is no differentiation into dendrites and axon, and no neurilemma is present.

The fibres usually appear varicose. The larger varicosities, at least, are due to toxic effects of the methylene blue. The fibres may be thick or thin, the distinction depending on the distance of the fibre from the parent cell. At the cell all the fibres have the same thickness.

The fibres may run parallel, cross each other obliquely or transversely, or commonly one fibre twists itself round another. Where the fibres cross each other they may lie in intimate contact, one of them showing a thickening. Fibres may also lie in close contact with the surface of nerve cells. Sometimes an ending resembling a "bouton" was seen. Intertwining between the fibres is a characteristic and frequently observed relation. Fusion does not occur, no true nerve net being formed. The intertwining and other intimate contacts between nerve fibres and fibres and cells are believed to be of synaptic significance.

Pericellular nerve endings on muscle occur; they are comparable to the endings on unstriped muscle cells in mammals. Neuro-sensory cells were also observed, but the relation of their processes to the general nerve plexus could not be determined.

The present observations confirm the histological work of Schäfer (1878) and Bozler (1927) and correlate favourably with the physiological findings of Pantin (1935). They are not in accordance with those of the majority of observers, whose descriptions have led to the general acceptance of the faulty notion that the coelenterate nervous system is a nerve net.

J. A. H.

\section{On the Mantle Cavity and its Contained Organs IN THE LoRicata (Placophora)}

\section{By C. M. Yonge}

\section{Quart. Fourn. Micr. Sci., Vol. Lxxxi, 1939, pp. 367-90}

Study of the course of the water currents in the mantle cavity of three species of the Chitonida and one species of the Lepidopleurida revealed that inhalant openings are created anteriorly or laterally by local raising of the girdle. The single exhalant opening is always posterior and confined to the region between the last pair of gills. The exhalant current carries with it the genital and excretory products and, in the Chitonida, the faeces. The functional division of the mantle cavity into inhalant and exhalant chambers is brought about by the bridging of the pallial grooves in the region of the pallial folds by the post-anal (and adanal) gills. Though modified the gills possess the typical structure and ciliation of true ctenidia. They are to be regarded as multiplied ctenidia and not as secondary structures. Four possible tracts of mucous glands in the pallial grooves are concerned with the consolidation of sediment; of these 
the pallial tracts are possibly homologous with the hypobranchial glands in the Prosobranchia. Osphradia, possibly homologous with those in the Gastropoda, occur in the majority of the Chitonida ; in the Lepidopleurida they are replaced by branchial and lateral sense organs. All are similar in structure and as likely to be concerned with the estimation of sediment as with olfactory functions previously ascribed to them. The Loricata probably evolved between tidemarks, their characteristic structure being admirably fitted for life on the shore.

C. M. Y.

\section{The Protobranchiate Mollusca; a Functional Interpretation OF THEIR STRUCTURE OF EVOLUTION}

\section{By C. M. Yonge}

Phil. Trans. Roy. Soc. London, B, Vol. ccxxx, 1939, pp. 79-147

The Protobranchia represent the one unquestionably natural group within the Class Lamellibranchia. The large foot permits movement into and through a soft substratum. Feeding, except in the modified Solenomyidae, is by means of the palp proboscis which collects organic detritus. In these respects the structure of the Protobranchia probably corresponds closely to that of the primitive Lamellibranchia, the evolution of the palp proboscides permitting retreat of the mouth from the substratum and the enclosure of the body within the bivalve shell. This involved life on a soft substratum, so that the apparently specialized foot is probably primitive for the Lamellibranchia.

The Nuculidae are the most primitive of existing Protobranchia, having an anterior inhalant current, primitive ctenidia essentially respiratory in function, and hypobranchial glands. Conditions are essentially similar in the Solenomyidae, but the ctenidia are enlarged as feeding organs. The Nuculanidae possess highly specialized "pumping" ctenidia forming delicate septal membranes, the filaments being united by complex ciliated junctions to each other and to the siphonal septum. The inhalant current is posterior and siphons occur which in different species show interesting stages in the conversion of ciliary into tissue junctions. Rejection of sediment from the mantle cavity is by cilia, except in the Solenomyidae, where it is brought about by the intucking of the ventral, uncalcified regions of the shell.

The alimentary canal is correlated in structure with the nature of the food particles collected by the palps. There is a dorsal crushing region lined with chitin and a ventral "style-sac" region which secretes mucus. Particles are embedded in this to assist triturition and the formation of faeces. There is no amylase and so no extracellular digestion. The digestive diverticula are organs of intracellular digestion. They consist of paired masses except in the Nuculanidae, where there is an additional mass of wide diverticula opening near the 
entrance of the oesophagus, and into which larger particles enter. There are no wandering phagocytic cells. The intestine and rectum are concerned exclusively with the consolidation of faeces.

The nature, interrelationships, systematic position and evolution of the Protobranchia are discussed.

C. M. Y.

\section{Fused NeUrons and Synaptic Contacts In THE Giant Nerve Fibres of Cephalopods}

\section{By J. Z. Young}

Phil. Trans. Roy. Soc. London, B, Vol. ccxxIx, 1939, pp. 465-503

A full description is given of the system of giant nerve fibres by means of which Loligo produces its rapid movements through the water. The whole system is operated by a pair of very large cells which lie in a hitherto undescribed lobe, the lobus magnocellularis. This lobe contains other large cells controlling the movements of the arms, and thus constitutes a higher motor co-ordinating centre. A peculiar feature of the giant fibre system is that in two places the processes of separate nerve cells fuse completely, contrary to the doctrine of the neuron theory. But in other parts of the system there are synaptic junctions at which it is very clear that no fusion takes place. The neurons between which fusion does occur always work together in life, and the case is therefore the exception which proves the rule of the neuron theory, showing that nerve fibres can fuse, but normally do not do so unless they invariably work together. The whole giant fibre system shows the extreme development of a neuromuscular mechanism for producing movement rather than tonus. Contractions are initiated by the action of the minimum possible number of motor units, and a single impulse is able to set the whole system in action. Such a system, though not well suited for the production of finely graded movements, allows the development of few, large and hence rapidly conducting fibres. The combination of speed with fine gradation of movement is only possible in animals, such as Vertebrates, in which rapid conduction is obtained by thickness or special structure of the myelin sheath, rather than by increased diameter of the fibres.

J. Z. Y. 